\title{
Promoting Shifts in Personal Narratives and Providing Structures of Support: Transitions of Incarcerated Children in England and Wales
}

\section{Tim Bateman and Neal Hazel}

\begin{abstract}
Recidivism rates for children leaving custody in England and Wales have remained stubbornly high, despite intense policy interest and some promising short-term initiatives. In this chapter, it is argued that the major challenge to improved outcomes has been the widespread failure of service providers to adopt lessons from research. This failure, we maintain, has been due to the lack of a conceptual understanding of how resettlement intervention effects positive change in children, leading to confusion as to service aims and what good practice looks like. Based on the existing knowledge base, from a six-year study titled, Beyond Youth Custody, it was concluded that effective resettlement should be reconceptualized as personal and practical support, that facilitates a shift in the child's personal narrative from pro-criminal to pro-social. Five characteristics for practice necessary to promote this shift are identified, which are compared to the Taxonomy for Transition Programming 2.0.
\end{abstract}

Keywords Youth resettlement $\bullet$ Re-entry $\bullet$ Policy failure $\bullet$ Personal narratives $\bullet$

T. Bateman

Institute of Applied Social Research, University of Bedfordshire, University Square, Luton, United Kingdom. e-mail: tim.bateman@beds.ac.uk

N. Hazel

Centre for Applied Research in Health, Welfare and Policy, University of Salford, Manchester, United Kingdom. e-mail:n.hazel@salford.ac.uk 


\section{The Youth Justice System in the UK}

The United Kingdom (UK) comprises three separate jurisdictions for criminal justice purposes, England and Wales, Scotland, and Northern Ireland; each of which has its own distinct legislative provisions, administrative arrangements, practice frameworks, data collection, and terminology. This is particularly true in relation to the treatment of children in conflict with the law. The system of 'youth justice' looks entirely different in each of the jurisdictions, and the pathways into and out of detention are not easily comparable. The academic literature tends accordingly to address a particular jurisdiction rather than provide a UK-wide perspective. This chapter follows that convention by focusing on England and Wales, the jurisdiction which accounts for the bulk of the incarcerated child population.

\section{Youth Justice in England and Wales}

The minimum age of criminal responsibility in England and Wales is, at ten years, lower than any other jurisdiction in Western Europe outside of the United Kingdom. Despite considerable criticism internally from the academic, practice, and policy community, and externally from the United Nations Committee on the Rights of the Child, the governments of both main political parties (Conservative and Labour) have shown little appetite for raising the age at which children are considered criminally liable for their offending (Bateman, 2012). As a consequence, processing for criminal activities can be initiated while children are still in primary school.

Where prosecution ensues, criminal proceedings commence in the youth court that was established in 1992, as a replacement for the juvenile court. The former was distinguished from the latter by an extension to the age of defendants processed by it to include 17-year olds (Bateman, 2017a). Other legislative provisions were amended to ensure a consistent approach was taken pre-trial and post-sentence. From 1992 onwards, adulthood for criminal justice purposes has, for most purposes, been attained at 18 years of age. It should be noted that remand provisions and entitlements at the police station for 17-year-olds remained different to those for younger children until the current decade (Youth Justice Legal Centre, 2015). The juvenile justice system, or youth justice system as it is more commonly known within England and Wales thus deals with alleged offending by children aged 10 to 17 years inclusive (Watkins \& Johnson, 2009).

Primary responsibility for intervention with children convicted in criminal proceedings lies with youth offending teams (YOTs). YOTs are multi-agency bodies established under the Crime and Disorder Act of 1998, with a statutory responsibility for delivery of youth justice services, including the supervision of children sentenced to custody while in detention and post-release (Burnett, 2005). The legislative provisions require that the YOT membership includes, at minimum a: (a) local authority social worker, (b) probation officer, (c) police officer, (d) health representative and, (e) an education worker; but most teams are larger than this minimum (Youth Justice Board, 2015). The constitution of services at a local level also varies considerably.

The standard custodial sentence in the youth court takes the form of the detention and training order (DTO) (Nacro, 2007). A DTO becomes available for children aged 12 years or older whose offending is deemed by the court to be "so serious that neither a fine alone nor a community sentence can be justified" (Criminal Justice Act of 2003, section 152). The nature of offences that cross this threshold, however, varies from one area to another, leading to considerable inconsistencies in the use of custody (Bateman \& Stanley, 2002). Under the Crime and Disorder Act of 1998, children from the age of ten years may also incur such penalties, but the provision has never been implemented (Nacro, 2007). Where the child is below the age of 15 years, the court cannot pass such a sentence unless it also deems them to be a persistent offender (Criminal Justice Act of 2003, section 52). There is no statutory definition of persistent offending in this context, increasing the potential for justice by geography (Nacro, 2007).

The court specifies the length of the DTO, typically between four and 24 months, half of which is, by default, served in custody with the remainder is subject to community-based statutory supervision. There is provision for early or late release depending upon assessed risk, and the child's progress against his or her training plan (Nacro, 2007). Longer sentences, of more than two years, are available for the relatively small number of children sentenced in the Crown court (an adult venue) for offences referred to, as 'grave crimes', for most purposes those offences for which the adult maximum is 14 years or longer (Sentencing Council, 2017). Residential burglary, handling stolen goods, robbery and wounding with intent, for instance, can all fall into the category of grave crimes if the youth court considers them to be sufficiently serious that jurisdiction should be refused. In such cases, the maximum term of imprisonment, and arrangements for release, are the same as those which apply to adult defendants.

Children convicted of grave offences are automatically released at the half way point of their sentence but are required to comply with licence conditions for the duration of the order. The Crown court also has more extensive custodial powers in the form of an extended sentence. This can be imposed in relation to children who are deemed to be dangerous because they have committed a serious sexual or violent offence and pose a "significant risk to the public of serious harm" from further offending (Sentencing Council, 2017, p. 8). The maximum sentence 
length, and release provisions, are again equivalent to those applicable to adults. Children subject to an extended sentence are released after two-thirds of the order has been served and are subsequently subject to post-custody supervision for a maximum of five years in the case of a violent offence, or eight years where the offence is a sexual one (Bateman, Hazel, \& Wright, 2013).

Children charged with murder must be tried in the Crown court and, where convicted, are subject to a mandatory penalty of Detention at Her Majesty's Pleasure (Nacro, 2004). This is the functional equivalent to an adult mandatory life sentence. Once the tariff is set by the court, and the minimum period to be served in custody has expired, release is at the discretion of the Parole Board. Individuals so released remain subject to supervision for the remainder of their lives. During 2015 - 2016, these three types of long-term sentences comprised, in combination, $16 \%$ of all custodial disposals imposed on children (Ministry of Justice/ Youth Justice Board, 2017). However, since children subject to such orders remain in secure conditions for longer than those detained under a DTO, they account for more than a quarter of the imprisoned children population at any one time (Youth Justice Board, 2017a).

Children subject to custody are detained in what is known as the 'secure estate'. This comprises three types of institutions: young offender institutions (YOIs), secure training centers (STCs), and secure children's homes (SCHs). These institutions differ markedly in terms of size, staff to child ratio, ethos, and the age range of young people which they accommodate (Bateman, 2016). In recent years, there has been considerable criticism of the conditions under which children are held, particularly in YOIs and STCs (see for example, Her Majesty's Chief Inspector of Prisons, 2017).

As a consequence of the legislative arrangements found in multiple Acts, all children sentenced to custody are obliged to undergo a period of statutory supervision in the community once they have been released. During this supervision period, they are subject to a range of compulsory conditions, some of which are standard, and others specific to the individual which are detailed in the notice of supervision or 'licence' as it is more commonly known. Such conditions will outline expectations of contact with the YOT, and frequently contain additional obligations such as a curfew. National standards require that children attend a meeting with their supervising YOT officer on the day of release, and specify a minimum number of supervisory contacts thereafter, between two and eight per month, depending on the level of assessed risk of reoffending (Youth Justice Board, 2013). Children who fail to comply with the requirements of supervision in the community may be returned to detention for the remainder of their order (Bateman et al., 2013). This provides a statutory framework for the process of transition back to the community, albeit that the element of compulsion entailed is not necessarily conducive to effective engagement (Bateman \& Hazel, 2013).

\section{Rate of Involvement in the Youth Justice System}

In April 2017, 909 children were detained in custodial institutions compared with 2,840 ten years earlier: a reduction in excess of two thirds (Youth Justice Board, 2017a). The rate of child custody over this period has accordingly declined from 55.1 per 100,000 children aged 10 to 17 years to 17.6. The figures include both those serving a custodial sentence, and those subject to custodial remand. Both populations have fallen markedly in the recent period, but the pattern of decline has been different. Custodial sentences began to tail off from 2002 onwards, but this shift was not reflected immediately in an equivalent decrease in the remand population. Indeed, as a consequence of a continued expansion in custodial remands, the number of children incarcerated at any one time continued to grow until 2008. Once the remand population began to contract, however, it did so more rapidly than the sentenced population. As a consequence, by 2015-2016, the proportion of the imprisoned population on remand had returned to earlier levels accounting for slightly more than one fifth of the total (Bateman, 2017b).

\section{'Resettlement' in England and Wales}

In England and Wales, the process of transitioning from custody to community is commonly known as resettlement. This expression is itself of relatively recent origin, even if the range of activities encompassed within it have a considerably lengthier history (Lewis, Vennard, Maguire, Raynor, Vanstone, Raybould, \& Rix, 2003). The term resettlement appeared for the first time in a Home Office (1998) consultation paper as the Government's preferred nomenclature for what had previously been known as 'throughcare' or 'aftercare', depending on the whether the subject was still in custody or had been released.

The change in terminology to describe the transition period reflected, in part, a recognition of the importance of joining up services provided in custodial institutions with those offered in the community (Home Office, 1998). It was also a manifestation of hardening attitudes towards offenders, associated with a 'punitive turn' experienced across a number of Western jurisdictions (Muncie, 2008). This, eschewed notions of caring as being outside the legitimate remit of the criminal justice system (Raynor, 2004). Nonetheless, by highlighting the need to resettle those whom the state deprived of their liberty, the shift had the advantage of illuminating the disruptive nature of the custodial experience. It also highlighted the necessity of repairing the harms associated with deprivation of 
liberty even if, in many cases, it wrongly implied that individuals were 'settled' prior to incarceration (Bateman et al., 2013).

At a policy level, the focus on resettlement has become more pronounced in recent years, particularly as regards children. Indeed, part of the rationale for the introduction of the DTO as the standard custodial penalty for children was that the YOT officer responsible for supervising the community element of the order "would also be involved in the planning and supervision of the custodial element" (Home Office, 1997, para 6.17). The DTO was intended to ensure a seamless intervention that offered a continuity of provision from the point of entry to the custodial institution, into the community, and beyond (Hazel et al., 2002). The extent to which this vision has been realized in practice is, of course, an empirical question that receives attention below.

\section{Recent Resettlement Initiatives}

The renewed focus on transitions has stimulated a number of often short-lived practice initiatives, akin to Taxonomy area of program structures (Kohler, Gothberg, Fowler, \& Coyle, 2016). These initiatives included: (a) the Resettlement and Aftercare Provision, initially targeted at young people leaving custody with high levels of substance misuse needs (Galahad SMS, 2010); (b) the Resettlement, Education, Support, Employment and Training (RESET) initiative, which piloted a range of different approaches in three areas (Hazel, Liddle, \& Gordon, 2010); and (c) funding for local authorities in areas of high youth incarceration to establish resettlement consortia with their neighbors to integrate planning and take advantage of economies of scale (Hazel, Wright, Liddle, Renshaw, \& Gray, 2012). It is apparent from the evaluations of these initiatives that each was able to demonstrate elements of promising practice which has indubitably contributed to an emerging evidence base in relation to youth resettlement (Hazel \& Liddle, 2012). This confirms that well-formulated resettlement practice can make a positive difference to outcomes for incarcerated children (Bateman et al., 2013), while generating long-term savings for the public purse (Renshaw, 2007).

Mainstreaming the learning from the above successful pilots has proved problematic, with short-term funding generating problems of sustainability and limited roll-out. Outside pilot areas, reoffending rates of children following release from custody have remained stubbornly high (Bateman, 2016). Such poor outcomes should be viewed in the context of shifts in youth justice in England and Wales over the past ten years, which have altered substantially the nature of the resettlement terrain, and the challenges which it poses to policy and practice. Most importantly perhaps, there has been a dramatic decline in the number of children subject to formal criminal justice processes (Bateman, 2017b). This has been reflected in a comparable fall in the custodial population, signaling a sharp reversal of a trend that saw sustained increases in child incarceration over the previous decade and a half (Bateman, 2017b).

While the decreased use of custody is obviously welcome, it has brought with it a number of additional challenges to those which are typically associated with supporting resettlement, such as housing, education and employment, family breakdown, substance misuse, and financial uncertainty (Farrant, 2006). In particular, as children whose offending was of a less serious or persistent nature have increasingly been diverted from imprisonment, those who continue to be incarcerated are more entrenched in delinquency, with a more extensive criminal history (Bateman \& Hazel, 2014a). This is evident in the increased average length of custodial episodes from an average of 76 days in 2006-2007 to 118, in the year ending March 2016 (Ministry of Justice/Youth Justice Board, 2017).

Longer sentences provide a greater window of time in which to provide rehabilitation interventions. Longer sentences, however, also increase the prospect of breaching licence conditions under which they were released at the discretion of the parole board, as period in the community under statutory YOT supervision becomes extended. This has led to a rise in returns to custody for non-compliance (Bateman \& Hazel, 2014a). Moreover, surveys of children in custody have shown rises in the proportion who report problems with emotional and mental ill-health, and who consider that they will have difficulties on release (Simmonds, 2016).

At the same time, the experiences of children within the secure estate have deteriorated. For instance, in 2015 - 2016, almost half (46\%) of boys within young offender institutions reported that they had felt unsafe within the establishment: the highest recorded level since this data was first collated in 2006-2008 (Simmonds, 2016). The fall in the child population in the secure estate has been accompanied by the closure of a considerable number of custodial institutions, leading to an increase in the average distance of placement from home. This exacerbates difficulties in maintaining, supporting, and nurturing links with families and communities that are crucial to successful transitions. Distance also impacts the involvement of these stakeholders in transition planning: one of the Taxonomy's five key areas. A recent study has confirmed that children who are held further from home receive fewer visits from professionals, family members, and friends (Her Majesty's Inspectorate of Prisons, 2016).

The decline in the use of custody, however, has not been experienced equally by all groups of children. For instance, although reliable data in this regard are hard to come by (Laming, 2016), it appears that children in local authority care are significantly overrepresented in the secure estate, and that the extent of overrepresentation has increased in recent years (Simmonds, 2016). The evidence-base is starker in relation to children of black and 
minority ethnic (BME) backgrounds. In 2006, children of BME backgrounds constituted slightly less than a quarter of the total custodial population; in 2016, the equivalent figure was 42\% (Ministry of Justice/Youth Justice Board, 2017a).

The import of these recent developments notwithstanding, perhaps the greatest challenge for resettlement policy and practice is that, over the longer-term, evidence of improved outcomes is difficult to find. While it should be acknowledged that reoffending is a blunt measure of effectiveness (Bateman, 2010), reducing 12-month recidivism rates is one of three high-level targets for the youth justice system in England and Wales, and the only one of direct relevance to resettlement (Youth Justice Board, 2017b). In spite of the increased profile of resettlement, reoffending, in particular for short sentences which continue to account for the majority of custodial episodes, has shown no downward trend. In 2004, $76.7 \%$ of children sentenced to custody for six months or less reoffended within one year of release: in the year ending March 2015, the equivalent figure was 77.2\% (Ministry of Justice/Youth Justice Board, 2017a).

Other less formulaic indicators are equally troubling. Relatively few children leaving custody are able to access appropriate education, training, or employment, and although it is recognized that a substantial proportion of the custodial population will not be able to live with their families when they return to the community, alternative accommodation arrangements are rarely in place until shortly before release (Bateman et al., 2013). A recent inspection of resettlement practice with children concluded:

The combination of a lack of suitable, settled and supported accommodation; a deficiency in the services to meet mental health and substance misuse issues and an absence of meaningful ETE or other constructive activities did not give them an opportunity to make a success of that transition. On the contrary, it made it more likely that they would fail'. (Her Majesty's Inspectorate of Probation, 2015, p. 18)

\section{'We know the solution ... why on Earth is it not being done?'}

The above question was one posed by Her Majesty's Inspectorate of Probation $(2015$, p. 4$)$ in response to the findings of a thematic inspection of resettlement practice with children in England and Wales. The inspection team included one of the authors of this chapter, Neal Hazel. The team concluded that the poor outcomes for the cases included in its inspection were the result of policymakers and practitioners not putting into practice the messages from the research knowledge-base. Notwithstanding small pockets of excellent work, the overall resettlement landscape was disappointing. The following points were raised in the report:

- Work with children in custody was not future orientated, focused on preparation for the transition back into the community, but was restricted to what was routinely available within the institution in terms of educational provision and behavior management;

- Plans were too often an end in themselves, devoid of meaningful content; and children, who frequently had little input in developing such plans and recognized their 'tick box' nature, became disengaged and disenchanted as a consequence;

- Resettlement work in the community frequently commenced too late and did not build on progress achieved in detention;

- Three-quarters of children did not fully comply with expectations of post-custody supervision and were thus liable to breach and potentially a return to custody; and

- Key staff did not fully understand, or value, each other's roles and accordingly did not work effectively together. (p. 6)

The inspectors gave examples of poor practice that demonstrated the potential implications of failing to provide services that are future-orientated and focused around the child. Unsurprisingly, in this context, outcomes for children, in terms of accommodation, education, training or employment, substance misuse, physical or mental health and rates of reoffending were for the most part rated as 'poor'. These findings were described as, "shocking because we have known for at least a decade what helps children leaving custody to stop offending" (Her Majesty's Inspectorate of Probation, 2015, p. 4).

Given the attention that has been devoted to the issue of transitions over the recent period, the mismatch between aspirations and the situation on the ground requires further investigation. If there has been a clear failure to overcome the "barriers to effective resettlement" (Bateman et al., 2013, p. 11), the question arises as to why evidence from research on resettlement has not been incorporated into mainstream practice. A potential explanation of that failure, and an alternative vision of how interventions to support transitions might be conceptualized, are offered below.

\section{The Policy and Practice of Transitions: Disparate 'Good Practice'}


National standards for youth justice are published by the Youth Justice Board for England and Wales, a nondepartmental body established by the Crime and Disorder Act of 1998, "to monitor the operation of the youth justice system and the provision of youth justice services" (s41(5) (a)). The standards include details of what is required of practitioners from a range of agencies when children are incarcerated, which have a direct bearing on resettlement. For instance, in recognition of the fact that preparation for release should commence at an early stage, the allocated YOT worker is expected to attend (and jointly chair) an initial planning meeting within ten days of the imposition of any custodial sentence. This provides an instance, albeit rather limited example of interagency collaboration, an area of the Taxonomy. The resulting plan should take account of what will happen to the child on release and include, among other considerations, arrangements for:

- $\quad$ education, training and employment;

- $\quad$ offending behavior work;

- the provision of suitable accommodation;

- health and mental health provision;

- $\quad$ provision of support for dealing with finances, debts and benefits;

- $\quad$ engaging with parents/carers and;

- details of reporting arrangements on the day of the child's release.

Sentence plans must be reviewed at least every three months, and a final release preparation meeting must be convened two weeks prior to the transition to the community. To ensure continuity once the child has left custody, a post-release review must be held within one month of release, and there is an expectation that custodial staff will attend (Youth Justice Board, 2013).

To a large extent, national standards are concerned with minimum expectations for procedural requirements, rather than guidance on effective practice. Further elaboration is, however, provided in the Board's Case management guidance on custody and resettlement, which acknowledges the complexity of the resettlement task and outlines seven 'pathways' that should be considered to ensure successful transition of children from custody to the community. The pathways are a response to evidence, derived from the 'risk factor paradigm' (see, Farrington, 2002), that identifies risks associated with further offending in anticipation that addressing such factors will reduce recidivism, as follows:

- accommodation;

- $\quad$ education, training and employment;

- health;

- $\quad$ substance misuse;

- the involvement of families;

- financial stability and;

- $\quad$ case management. (Youth Justice, 2014)

Case management is a cross cutting theme intended to ensure an integrated approach across each of the other pathways, and to broker engagement of a broad range of partners. This reflects research findings that criminal justice agencies cannot deliver effective transitions in isolation, and that co-ordination of multi-agency support and commitment is a prerequisite of effective resettlement intervention (see, for instance, Hazel et al., 2010). This aligns with the Taxonomy area of interagency collaboration.

Despite the criminological underpinnings of the Board's pathways, it is possible to discern some degree of congruence with the Taxonomy derived from the education paradigm, involving the five practice areas of youthfocused planning, youth development, interagency collaboration, family engagement, and program structures. Both emphasize the importance of family engagement and interagency collaboration. The education, training and employment pathway is similarly reflected in elements of the youth development area of the Taxonomy. Moreover, youth justice practice in England and Wales, including planning for resettlement, is predicated on centrally mandated, structured assessment. While this might be seen as mirroring the importance attached to assessment within the Taxonomy area of effective youth development, it is clear that assessing for resettlement is intended (primarily) to capture criminogenic need rather than educational aptitude or welfare privation (Baker, Kelly, \& Wilkinson, 2011).

Conversely, the Board's framework places little emphasis on features which appear central to the Taxonomy, such as youth self-determination, and future focus in the youth-focused planning area. This is perhaps because it is embedded in an understanding of youth crime that draws heavily on what has been referred to as the 'risk factor prevention paradigm' (Haines \& Case, 2015, p. 6). More significantly, unlike the Taxonomy, the resettlement framework does not obviously describe an iterative process.

In our view, the key to unlocking the dilemma of continued poor outcomes is to recognize that the Board's model encourages an inadequate conception of resettlement which views good practice in terms of a raft of disparate principles, that somehow combine to deliver effective transitions. There has been no attempt to identify a high-level aim for resettlement beyond preventing reoffending; and no theory of change has been elaborated 
that might help to provide an overarching framework within which individual principles might cohere (Hazel, Goodfellow, Liddle, Bateman, \& Pitts, 2017).

\section{A Local Challenge: The Problem of Girls}

It cannot be assumed that the mainstream research literature on effective transitions applies in an unmediated form to girls. Indeed, to a large extent, that literature has tended to overlook the particular circumstances of young women in custody. Within England and Wales, this omission has been replicated to a considerable extent in both policy and practice. While the same could be said for women in the justice system more generally, girls are doubly disadvantaged because they fall "between two stools": their specific needs are overlooked not only by researchers considering gender, but also those whose primary focus is age (Burman \& Batchelor, 2009, p. 270). This gap is especially concerning since the relatively limited evidence that does exist in relation to adult offending suggests that what constitutes effective practice with males may not work with their female counterparts (Bateman \& Hazel, 2014b; Blanchette \& Brown, 2006; Cann, 2006).

It is clear that girls' criminal behavior differs from that of boys in important respects. Smith and McAra (2004) note the following differences. Firstly, girls are significantly less likely to commit offences or come to the attention of the criminal justice agencies. Secondly, when they do get into trouble, they engage, on average, in criminal activities that are less serious than boys. Thirdly, they tend to grow out of crime at an earlier age. Lastly, they are less likely to reoffend following youth justice intervention. Thus, in 2016, girls accounted for less than $13 \%$ all of children entering the youth justice system. They were more likely than boys to be processed for theft $(26 \%$ compared to $18 \%)$, and were significantly less likely to be reconvicted within a year (27.6\% compared with a rate for boys of 40.3\%) (Bateman, 2017b).

At the same time, there is evidence that the etiology of girls' delinquent activity differs in important respects from that of boys, as a consequence of their gendered location within the social structure, and that those entering the youth justice system are more vulnerable than their male counterparts on a range of indicators than their male counterparts (Bateman \& Hazel, 2014b). This is particularly true of girls in custody. Recent analysis by the Youth Justice Board (2017c) of admissions to the secure estate indicate that, among others, there were assessed concerns in relation to:

- Suicide or self-harm for $63 \%$ of girls and $30 \%$ of boys

- Mental health for $41 \%$ of girls and $33 \%$ of boys

- Sexual exploitation for $60 \%$ of girls and just $6 \%$ of boys.

Moreover, historical experience of child incarceration confirms that the treatment of girls is particularly sensitive to shifts in policy and practice. Between 1992 and 2001, for instance, youth custodial sentencing rose by more than $90 \%$, in spite of the fact that youth crime was falling. The impact on girls of this punitive dynamic was considerably more alarming, with an increase in sentences of imprisonment imposed on females of $500 \%$, albeit from a low baseline. Conversely, with the onset of decarceration from 2008 onwards, the fall in the number of girls detained in the secure estate has dropped much more sharply than the number of boys (Bateman, 2017b). In April 2017, there were just 30 girls in custody, an $86 \%$ reduction by comparison with the peak of girls' imprisonment in April 2008 (Youth Justice Board, 2008a). This welcome reduction poses particularly acute problems in terms of placement and resettlement. Ensuring the particular needs of girls are met in an overwhelmingly male custodial environment is challenging. Youth justice staff both in custody and the community have limited expertise of female transitions; and distance from home is, on average, significantly greater than for boys (Bateman \& Hazel, 2014b).

The real-life case study derived from Her Majesty's Inspectorate of Probation report (2015) shown below, derives from the thematic inspection discussed above and is instructive in highlighting some of the some of the difficulties that arise in providing effective resettlement in general and of accommodating the different challenges that emerge in facilitating the transitions of girls in particular.

\section{Case Study: Helen}

Helen was imprisoned for a violent offence. She had a history of sexual abuse and had been assessed as being at continued risk of sexual exploitation. She had a strained relationship with her mother but was nonetheless placed 200 miles away from her home address. Helen requested a transfer to an establishment closer to home, but none was arranged. As her release date approached, her mother had neither visited nor attended any planning meetings. Helen expressed a desire to live near her mother and boyfriend on transfer return to the community, but was told, two days prior to her release, that children's social care intended to place her 20 miles away from her family. Although she had indicated how important it was for her to be kept occupied, no plans for constructive activities were in place at the point of transfer for her return to the community. 
Helen went missing within a day of leaving custody, and her whereabouts were not known for five weeks. When she was arrested and returned to custody for a new offence, it transpired that she had been spending her time between her mother's and boyfriend's accommodation. The inspection team concluded that while much good work was undertaken in relation to Helen's rehabilitation while in custody, the location of the custodial placement, late planning, a failure to take account of the child's wishes and her family circumstances all made "her release plans fragile and did not offer ... the best opportunity to successfully resettle" (Her Majesty's Inspectorate of Probation, 2015, p. 20).

\section{Resettlement Conceived as Promoting a Shift in Personal Narrative}

In this section, an alternative conception of resettlement is proposed. It is derived from Beyond Youth Custody (BYC), a six-year study from 2012, designed to add to the evidence base and promote improved policy and practice in relation to resettlement of young people leaving custody. The initiative is a partnership involving Nacro (a local social justice charity), Applied Research in Community Safety (ARCS), and the Universities of Salford and Bedfordshire. The study is funded by the Big Lottery Fund from 2012 to 2018. Arguably, the evidence from that program of work, and the model of resettlement developed from it, helps to illuminate why youth resettlement in England is failing to deliver improved outcomes, despite the considerable attention devoted to transitions in the recent period.

The BYC model rejects established understanding of resettlement as an attempt to compensate for deficits in the child and their environment, which increase the risk of continued delinquency. It proposes that the resettlement process, where successful, is better conceived as representing a journey for the child, involving a shift in personal narrative and identity. Their journey should no longer be viewed simply as following a sentence path, although the move from custody to community is a critical point in time (see, Bateman \& Hazel, 2015). Instead, it should be viewed as development for the child from a pro-criminal narrative conducive to offending, to a pro-social one that promotes a crime-free life and social inclusion. The more positive narrative is fostered and reinforced through involvement in constructive activities and interactions, and in the adoption of roles that promote it. The resettlement task is thus to facilitate the emergence of this future pro-social narrative and to empower the child to make positive behavioral and other choices.

In this sense, the BYC model centers on the young person's journey, and is arguably closer to the Taxonomy than the central government's prescriptions derived from an over-reliance on addressing risk. The former aligns with the Taxonomy's incorporation principles of youth development and youth-focused planning, since it implies a future orientation and building on the child's strengths and wishes. In contrast, the Board's guidance is predicated on addressing cognitive or social deficits, and contains little, if any, discussion on how providing accommodation or attending to education can assist the process of social integration. A unifying theoretical framework that seeks to go beyond such a restricted vision might be found in a desistance-based paradigm, that seeks to understand the resettlement process as an alteration in the personal narratives that young people use to frame their behaviors (Hazel et al., 2017).

In this context, while engagement is frequently acknowledged as a necessary precursor of effective resettlement work, it is too frequently understood as a technical exercise requiring practitioners to learn a range of skills and techniques that will maximize young people's co-operation. Within the youth justice system in England and Wales, such techniques frequently involve the threat of breach action (Mason \& Prior, 2008). From the child's perspective, however, there is a clear distinction between behavioral engagement, characterized by attending appointments as required, and emotional or cognitive engagement, where the child not only attends but has some investment in the activities undertaken or recognizes the longer-term benefits for themselves (Fredericks, Blumenfeld, \& Paris, 2004). These distinctions clearly have much in common with that drawn by Bottoms (2001), between instrumental and normative forms of compliance. In the BYC study, such insights have been drawn on to assimilate the multi-faceted nature of engagement into a three-stage, though not necessarily linear, model that allows a focus on the child's journey of shifting personal narrative (Bateman \& Hazel, 2013).

In the BYC model, the first stage involves the resettlement service engaging with the child: establishing a meaningful connection and enhancing motivation to become involved with the program to elicit behavioral engagement. The second stage involves the child engaging with the service; increasingly developing high quality relationships with staff, and identifying with the goals and objectives of intervention, so that he or she is emotionally engaged, and compliance becomes normative. This process of engagement both requires and contributes to alterations in the child's personal narrative. In the final stage, the child begins to engage in a constructive manner with the wider world outside of the resettlement program. This latter stage involves translating the potential, which the child has developed through the transition process, to integrate themselves into the wider world and mainstream service provision into a reality (Bateman \& Hazel, 2013). Success at this stage might be manifested by the young person engaging with constructive mainstream leisure pursuits, achieving stable accommodation, maintaining positive personal relations, moving into sustainable education training or employment, and desisting from offending. This manifestation would indicate the child having successfully 
embarked on a journey, in which his or personal identity has shifted. The unifying aim of resettlement policy, planning, and practice should be understood as the facilitation of this transformative process.

This conception of transition has a range of implications whose full explication is beyond the scope of this chapter (see Hazel et al., 2017 for an extended explication). Perhaps most importantly, it provides a model for understanding the significance of the various strands of 'effective' resettlement practice that have become the mainstays of government policy. In particular, it suggests that a holistic service will provide the child with two distinct, but reciprocal, forms of support.

Primarily, there is a need for personal support that initiates, guides, and sustains the child's journey. This helps them to identify their strengths, set goals, and plan a pathway towards them. It involves enabling a sense of agency that encourages the child to develop a sense of hope and investment in the future and a belief that they can achieve. Consistent and high-quality relationships are prerequisites of the provision of such support (Dowden \& Andrews, 2004).

Secondarily, to maximize its potential, personal support must be complemented by practical support that enables the child's shift to a constructive identity. This must ensure that the requisite pathways to their goals, including accommodation, education, training and employment, financial stability, and healthcare are available to the child, and that obstacles are eliminated, or reduced and made navigable. This constitutes a recognition of the fact that desistance is an interaction between the choices made by individuals and the wider social, political, and environmental forces, that are beyond their immediate control and constrain the choices that are available to them (Farrall \& Bowling, 1999). Both forms of support are required throughout the child's journey: from the point of entering custody, the transition to the community, throughout post-custody supervision, and into the future once the sentence is complete.

Significantly, in broad outline at least, this combination of personal and practical support to enable a shift in identity has the potential to address the challenge posed by girls in the system. Different pathways into and out of offending, focuses on promoting agency and commits services to work with children in the spirit of co-production. In Helen's case, discussed above, the model would have (a) necessitated a recognition of the importance of retaining links with her family; (b) ensured that placement decisions, both in custody and in the community supported maintaining links; and (c) prioritized Helen's own perceptions of her needs and wishes on release. Supporting a shift towards a new pro-social identity would necessarily require agencies working with vulnerable girls, like Helen, to focus on identifying activities, roles, and relationships that would empower them to make positive behavior choices (Bateman \& Hazel, 2014b). Interventions would not be provided for their own sake, nor be gender inappropriate, but would be chosen to facilitate this empowerment, including involving family and friends in ways that help to reinforce identity development (Hazel, Goodfellow, Wright, Lockwood, McAteer \& Francis, 2016).

\section{Implications for Practice: The Five Characteristics of Effective Resettlement support}

Experience in England and Wales suggests that resourcing resettlement activities that address the risk factors associated with offending behavior may not be sufficient to guarantee successful transitions of children from custody to the community. Focusing on the child's future rather than attempting to ameliorate past deficits requires a rather more complex understanding of the resettlement task as one whose primary function is to promote a shift in the child's identity and facilitate the child's agency in developing a constructive personal narrative. Mainstreaming such a conception of resettlement will pose considerable challenges for policy makers and practitioners who have become accustomed to delivering discrete intervention packages.

The researchers involved in the BYC program have concluded that to enhance the prospect of intervention achieving a shift in personal narrative requires that personal and practical support should be characterized by a number of qualities. Like the Taxonomy, these qualities are distillations from the evidence-base, albeit around resettlement rather than transition to post-school life for children with disabilities. Resettlement support should have the following five characteristics, each of which is arguably consistent with the five areas of the Taxonomy, reflecting a shared future-focus:

1. The transition plan must be co-created. The child's input is integral to intervention planning. A participatory approach is a precursor of effective engagement, and crucial to the development of constructive personal identity through fostering confidence, self-esteem, and a sense of agency (Wright, Francis, \& Goodfellow, 2014). There are clear similarities here with the Taxonomy area of youth-focused planning, in particular, the focus on selfdetermination. The intervention should also involve informal supporters, who can offer practical support and provide opportunities to reinforce personal narratives for the future but also offer practical support (Hazel et al., 2016). This mirrors the Taxonomy area of family engagement.

2. Transition planning and support is consistent with intervention planning, spanning the whole of the transition journey from the start of the sentence, or before, to beyond its end. Support provided while in custody is focused on preparation for release. Support provision in the community should build upon progress made in detention, in a seamless program. Wherever possible, the same staff remain with the child throughout, to enable the 
development of meaningful relationships, and to promote engagement. Elements of the Taxonomy area of program structure, particularly in early transition planning are discernible here.

3. Interventions must be customized, tailored to the child's circumstances. The diverse backgrounds from which children derive, and the associated impact of systemic disadvantage and barriers to achieving change must be taken into account. Each child's resettlement journey is necessarily unique; they have different strengths, goals, aspirations and anxieties. The wraparound, individualized, programming of support this implies is consistent with the Taxonomy area of youth-focused planning.

4. Transition planning and support is coordinated. The provision of customized packages of effective support requires an interagency response that reaches beyond the confines of the youth justice system and engages both with professional providers and informal networks of support including families, friends, and communities (Hazel et al., 2016). Evidence suggests that such partnership arrangements are unlikely to emerge organically but require carefully planned coordination. This characteristic of effective practice reflects the emphasis on coordination found in the Taxonomy area of interagency collaboration.

5. Interventions should be constructive and centered on exploring and reinforcing a positive identity. They should be future-focused and strengths-based, empowering, and motivating. On a practical level, this is redolent of the future-orientation of the Taxonomy areas of youth development and youth-focused planning, although these are not framed within a framework of identity or narrative shift.

The BYC model differs from the Taxonomy, however, in conceiving the resettlement transition more as a journey for the young person and less as an intervention timeline. There may be merit in future education research considering whether a similar conceptualization, embedded in youth engagement, might also be useful in understanding effectiveness in educational transitions.

\section{Conclusion}

Effective transitions are those which promote a journey involving a shift in personal narrative on the part of the child. The role of practice is to encourage, facilitate, and sustain that journey though the provision of personal and practical support. That practice must be characterized by a range of qualities that determine the extent to which support is efficacious. The Taxonomy of Transition Programming 2.0 is more comfortably aligned to this similarly future-focused model than to current policy guidance for resettlement in England and Wales. This suggests that messages from research on transitions tend to point in the same direction across education and youth justice.

Resettlement policy and practice in England and Wales has hitherto, while incorporating elements of what the BYC model implies, not been informed by a conceptual understanding that provides the requisite framework that enables these elements to cohere into a package designed to promote a shift in personal narrative. Without that understanding, interventions will, in the view of the authors, continue to be fragmented, focused on addressing risk, and ultimately fail to deliver successful transitioning that vulnerable children in custody require and deserve.

\section{Further Reading}

The main findings from the BYC program are contained in:

Bateman, T., Bateman, T., \& Hazel, N. (2013). Engaging young people in resettlement: Research report. London, England: Beyond Youth Custody.

Goodfellow, P., Wilkinson, S., Hazel, N., Bateman, T., Liddle, M., Wright, S. \& Pitts, J. (2017). Lessons from Youth in Focus: Research report. London, England: Beyond Youth Custody.

Hazel, N., Goodfellow, P., Liddle, M., Bateman, T., \& Pitts, J. (2017). 'Now all I care about is my future'. Supporting the shift: framework for the resettlement of young people leaving custody. London, England. Beyond Youth Custody.

Hazel N., Wright S., Liddle, M., Renshaw, J. \& Gray, P. (2012). Evaluation of the North West Resettlement Consortium: Final report. London: Youth Justice Board.

This report draws out lessons from a promising resettlement pilot.

Her Majesty's Inspectorate of Probation. (2015). Joint thematic inspection of resettlement services to children by Youth Offending Teams and partner agencies. Manchester, England: Author.

This publication offers a damning, but accurate, assessment of current resettlement practice.

Youth Justice Board. (2014). Custody and resettlement: Section 7 case management guidance. London, England: Author.

This publication provides an overview of existing resettlement policy.

\section{References}


Baker, K., Kelly, G., \& Wilkinson, B. (2011). Assessment in youth justice. Bristol, England: Policy press.

Bateman, T. (2010). Reoffending as a measure of effectiveness of youth justice intervention: A critical note. Safer Communities, 9(3), 28-35.

Bateman, T. (2012). Criminalising children for no good purpose: The age of criminal responsibility in England and Wales. London, England: National Association for Youth Justice.

Bateman, T. (2016). The state of youth custody. London, England: National Association for Youth Justice.

Bateman, T. (2017a). Youth justice. In J. Harding, P. Davies, \& G. Mair (eds.), An introduction to criminal justice (pp. 346-365). London, England: Sage.

Bateman, T. (2017b) The state of youth justice 2017: An overview of trends and developments. London, England: National Association for Youth Justice.

Bateman, T., \& Hazel, N. (2013). Engaging young people in resettlement: Research report. London, England: Beyond Youth Custody

Bateman, T., \& Hazel, N. (2014a). Resettlement of young people leaving custody: Lessons from the literature. Update March 2014. London, England: Beyond Youth Custody

Bateman, T. \& Hazel, N. (2014b). Resettlement of girls and young women: Research report. London, England: Beyond Youth Custody.

Bateman, T., \& Hazel, N. (2015). Custody to community: How young people cope with release: Research report. London, England: Beyond Youth Custody.

Bateman, T., Hazel, N., \& Wright, S. (2013). Resettlement of young people leaving custody: Lessons from the literature. London, England: Beyond Youth Custody

Bateman, T., \& Stanley, S. (2002). Patterns of sentencing: Differential sentencing across England and Wales. London, England: Youth Justice Board.

Blanchette, K., \& Brown, S. (2006). The assessment and treatment of women offenders. Chichester, England: Wiley.

Bottoms, A. (2001). Compliance with community penalties. In A. Bottoms., L. Gelsthorpe, \& S. Rex (eds.), Community penalties: Change and challenges (pp. 87-116). Cullompton, England: Willan.

Burman, M., \& Batchelor, S. (2009). Between two stools: Responding to young women who offend. Youth Justice, 9(3), 271- 285.

Burnett, R. (2005). Youth offending teams. In T. Bateman \& J. Pitts (eds.), The RHP companion to youth justice (pp. 106-112). Lyme Regis, England: Russell House.

Cann, J. (2006). Cognitive skills programmes: Impact on reducing reconviction among a sample of female prisoners. Research Findings 276. London, England: Home Office.

Crime and Disorder Act (1998).

Criminal Justice Act (2003).

Dowden, C., \& Andrews, D. A. (2004). The importance of staff practice in delivering effective correctional treatment: A meta-analytic review of core correctional practice. International Journal of Offender Therapy and Comparative Criminology, 48(2), 203-214.

Farrall, S., \& Bowling, B. (1999). Structuration, human development, and desistance from crime. British Journal of Criminology, 39(2), 253-268.

Farrant, F. (2006). Out for good: The resettlement needs of young men in prison. London, England: Howard League for Penal Reform.

Farrington, D. P. (2002). Developmental criminology and risk-focused prevention. In M. McGuire, R. Morgan, \& R. Reiner (eds.), The Oxford handbook of criminology (3rd ed.) (pp. 657-701). Oxford, England: Oxford University Press.

Fredricks, J., Blumenfeld, P., \& Paris, A. (2004). School engagement: Potential of the concept, state of the evidence. Review of Educational Research, 74(1), 59-109.

Galahad, SMS. (2010). Evaluation of resettlement and aftercare provision (RAP project). London, England: Youth Justice Board.

Goodfellow, P., Wilkinson, S., Hazel, N., Bateman, T., Liddle, M., Wright, S., \& Pitts, J. (2017). Lessons from Youth in Focus: Research report. London, England: Beyond Youth Custody.

Haines, K., \& Case, S. (2015). Positive youth justice: Children first, offenders second. Bristol, England: Policy Press.

Hazel, N., Goodfellow, P., Liddle, M., Bateman, T., \& Pitts, J. (2017). 'Now all I care about is my future'. Supporting the shift: framework for the resettlement of young people leaving custody. London, England. Beyond Youth Custody.

Hazel, N., Hagell, A., Liddle, M., Archer, D., Grimshaw, R., \& King, J. (2002). Assessment of the detention and training order and its impact on the secure estate across England and Wales. London, England: Youth Justice Board.

Hazel, N., Goodfellow, P., Wright, S., Lockwood. K., McAteer, L., Francis, V., \& Wilkinson, S. (2016). The role of family support in resettlement. London, England: Beyond Youth Custody. 
Hazel, N., Liddle, M., \& Gordon, F. (2010). Evaluation of RESET: A major programme for young offenders. London, England: Catch 22.

Hazel, N., \& Liddle, M. (2012). Resettlement in England and Wales: Key policy and practice messages from research. London, England: Youth Justice Board.

Hazel, N., Wright S., Liddle, M., Renshaw, J., \& Gray, P. (2012). Evaluation of the North West Resettlement Consortium: Final report. London: Youth Justice Board.

Her Majesty's Chief Inspector of Prisons for England and Wales. (2017). Annual report 2016-2017. London, England: HM Inspectorate of Prisons.

Her Majesty's Inspectorate of Prisons. (2016) The impact of distance from home on children in custody: A thematic review. London, England: HM Inspectorate of Prisons.

Her Majesty's Inspectorate of Probation. (2015). Joint thematic inspection of resettlement services to children by Youth Offending Teams and partner agencies. Manchester, England: HM Inspectorate of Probation.

Home Office. (1997). No more excuses: A new approach to tackling youth crime in England and Wales. London, England: Author.

Home Office. (1998). Joining forces to protect the public: A consultation paper. London, England: Author.

Kohler, P. D., Gothberg, J. E., Fowler, C., \& Coyle, J. (2016). Taxonomy for transition programming 2.0: A model for planning, organizing, and evaluating transition education, services, and programs. Kalamazoo, MI: Western Michigan University.

Laming, L. (2016). In care, out of trouble: How the life chances of children in care can be transformed by protecting them from unnecessary involvement in the criminal justice system. London, England: Prison Reform Trust.

Lewis, S., Vennard, J., Maguire, M., Raynor, P., Vanstone, M., Raybould, S., \& Rix, A. (2003). The resettlement of short-term prisoners: An evaluation of seven pathfinders. Occasional Paper 83 London, England: Home Office.

Mason, P., \& Prior, D. (2008). Engaging young people who offend: Source document. London, England: Youth Justice Board.

Ministry of Justice / Youth Justice Board (2017). Youth justice statistics 2015/16: England and Wales. London, England: Author.

Muncie, J. (2008). The 'punitive turn' in juvenile justice: Cultures of control and rights compliance in Western Europe and the USA. Youth Justice 8(2), 107-121.

Nacro. (2004). Children who commit grave crimes. London, England: Author.

Nacro (2007). The detention and training order: Current position and future developments. London, England: Author.

Raynor, P. (2004). Opportunity, motivation and change: Some findings from research on resettlement. In R. Burnett \& C. Roberts (eds.), What Works in probation and youth justice: Developing evidence based practice (pp. 217-233). Cullompton, England: Willan.

Renshaw, J. (2007). The costs and benefits of effective resettlement of young offenders. Journal of Children's Services, 2(4), 18-29.

Sentencing Council. (2017). Sentencing children and young people: Overarching principles and offence specific guidelines for sexual offences and robbery. London, England: Author.

Simmonds, J. (2016). Children in custody 2015-2016: An analysis of 12-18 year olds' perceptions in secure training centres and young offender institutions. London, England: HM Inspectorate of Prisons.

Smith, D. \& McAra, L. (2004). Gender and youth offending. Report 2, Edinburgh study of youth transitions. Edinburgh, Scotland: University of Edinburgh.

Watkins, M., \& Johnson, D. (2009). Youth justice and the youth court: An introduction. Hook, England: Waterside press.

Wright, S., Francis, V., \& Goodfellow, P. (2014). Young people and resettlement: Participatory approaches. A practitioner's guide. London, England: Beyond Youth Custody.

Youth Justice Board. (2013). National standards for youth justice services. April 2013. London, England: Author.

Youth Justice Board. (2014). Custody and resettlement: Section 7 case management guidance. London, England: Author.

Youth Justice Board. (2015). Youth offending teams: Making the difference for children and young people, victims and communities. London, England: Author

Youth Justice Board. (2017a). Youth custody data - April 2017. London, England: Author.

Youth Justice Board. (2017b). Annual report and accounts 2016/17. London, England: Author.

Youth Justice Board. (2017c). Key characteristics of admissions to youth custody April 2014-March 2016. London, England: Author.

Youth Justice Legal Centre. (2015). 17-year olds to be treated as children at police stations. Retrieved from: http://www.yjlc.uk/definition-of-arrested-juvenile-amended-to-include-17-year-olds 